\title{
Phytohormone Production Profiles in Trichoderma Species and Their Relationship to Wheat Plant Responses to Water Stress
}

\author{
María Illescas, Alberto Pedrero-Méndez (D, Marcieli Pitorini-Bovolini, Rosa Hermosa (D) and Enrique Monte *(i) \\ Institute for Agribiotechnology Research (CIALE), Department of Microbiology and Genetics, \\ University of Salamanca, Campus de Villamayor, C/Duero, 12, 37185 Salamanca, Spain; millesmor@usal.es (M.I.); \\ alberto.pedrerom@usal.es (A.P.-M.); m.bovolini@hotmail.com (M.P.-B.); rhp@usal.es (R.H.) \\ * Correspondence: emv@usal.es; Tel.: +34-923294500 (ext. 5119)
}

Citation: Illescas, M.;

Pedrero-Méndez, A.;

Pitorini-Bovolini, M.; Hermosa, R.;

Monte, E. Phytohormone Production

Profiles in Trichoderma Species and

Their Relationship to Wheat Plant

Responses to Water Stress. Pathogens 2021, 10, 991. https://doi.org/

$10.3390 /$ pathogens 10080991

Academic Editors: David Turrà,

Stefania Vitale, Sheridan Lois Woo and Francesco Vinale

Received: 6 July 2021

Accepted: 2 August 2021

Published: 6 August 2021

Publisher's Note: MDPI stays neutral with regard to jurisdictional claims in published maps and institutional affiliations.

Copyright: (c) 2021 by the authors. Licensee MDPI, Basel, Switzerland. This article is an open access article distributed under the terms and conditions of the Creative Commons Attribution (CC BY) license (https:/ / creativecommons.org/licenses/by/ $4.0 /)$.

\begin{abstract}
The production of eight phytohormones by Trichoderma species is described, as well as the 1aminocyclopropane-1-carboxylic acid (ACC) deaminase (ACCD) activity, which diverts the ethylene biosynthetic pathway in plants. The use of the Trichoderma strains T. virens T49, T. longibrachiatum T68, T. spirale T75 and T. harzianum T115 served to demonstrate the diverse production of the phytohormones gibberellins (GA) $\mathrm{GA}_{1}$ and $\mathrm{GA}_{4}$, abscisic acid (ABA), salicylic acid (SA), auxin (indole-3-acetic acid: IAA) and the cytokinins (CK) dihydrozeatin (DHZ), isopenteniladenine (iP) and trans-zeatin $(\mathrm{tZ})$ in this genus. Such production is dependent on strain and/or culture medium. These four strains showed different degrees of wheat root colonization. Fresh and dry weights, conductance, $\mathrm{H}_{2} \mathrm{O}_{2}$ content and antioxidant activities such as superoxide dismutase, peroxidase and catalase were analyzed, under optimal irrigation and water stress conditions, on 30-days-old wheat plants treated with four-day-old Trichoderma cultures, obtained from potato dextrose broth (PDB) and PDB-tryptophan (Trp). The application of Trichoderma PDB cultures to wheat plants could be linked to the plants' ability to adapt the antioxidant machinery and to tolerate water stress. Plants treated with PDB cultures of T49 and T115 had the significantly highest weights under water stress. Compared to controls, treatments with strains T68 and T75, with constrained $\mathrm{GA}_{1}$ and $\mathrm{GA}_{4}$ production, resulted in smaller plants regardless of fungal growth medium and irrigation regime.
\end{abstract}

Keywords: fungal phytohormones; gibberellin; auxin; cytokinin; ACC deaminase; drought

\section{Introduction}

The establishment of microbial symbioses to promote plant growth and nutrient acquisition by beneficial microbes have been correlated to the biosynthesis of plant growth regulators and phytohormones [1,2]. It is well established that, in addition to inducing host hormone synthesis, pathogenic and symbiotic fungi can also modulate the hormonal network of plants, as they produce by themselves small amounts of phytohormones to serve their purpose. Jasmonic acid (JA), auxin (indole-3-acetic acid: IAA), cytokinins (CK), gibberellins (GA), ethylene (ET), abscisic acid (ABA) and salicylic acid (SA) of fungal origin are involved in favoring tissue colonization and nutrient uptake, by means of plant development control and activation of signaling events during biotic and abiotic stresses [3]. Thus, auxin and GA producing endophytic fungi can enhance host plant growth and alleviate adverse effects of an abiotic stress, opening up the possibility of their use to improve agricultural productivity under adverse soil conditions [4]. In the same case is Trichoderma, a fungal biocontrol agent that includes species that are well known for their ability to produce fungal and oomycete cell wall degrading enzymes [5], scavenging reactive oxygen species (ROS) and causing plant cell wall hydrolysis [6,7] to facilitate the endophytic colonization of root tissues in competition with pathogens [8]. Selected Trichoderma species also produce effector molecules capable of triggering signaling cascades in the plant [9-11] that lead to the induction of systemic resistance to biotic and abiotic stresses as well as growth promotion $[12,13]$. In this regard, rhizosphere competent 
species have evolved to manipulate root development, plant immunity and stress tolerance by producing phytohormones [14]. It has been shown that T. atroviride, T. virens and T. harzianum produce IAA, T. parareesei produces SA and Trichoderma sp. produces IAA and GA without any inducers, although it is known that their production levels depend on the amount of tryptophan (Trp) present in the medium [15-21]. T. asperellum also releases ABA together with IAA and GA into the culture medium, and its application to cucumber promoted seedling growth and alleviated the effects of salt stress [22]. The production of IAA by T. harzianum has been related to the biocontrol of anthracnose disease and improved growth of sorghum plants [21]. The application of T. parareesei T6 or T. harzianum T34 to tomato seeds also improved the tolerance of plants to salt stress and enhanced the growth when plants grew under this adverse condition $[23,24]$. T. afroharzianum (formerly T. harzianum) T22 improved tolerance of tomato seedlings to water deficit [25]. The colonization of cocoa seedlings by T. hamatum DIS 219b enhanced seedling growth, altered gene expression, and delayed the onset of the cocoa drought response in leaves [26]. Similarly, T. atroviride ID20G inoculation of seeds ameliorated drought stress-induced damages by improving antioxidant defense in maize seedlings [27]. The same happened with the improved drought tolerance observed in rice genotypes inoculated with T. harzianum Th-56, in which the antioxidant machinery was activated in a dose-dependent manner [28].

IAA is the phytohormone that regulates the plant's development of the primary and lateral roots [29]. It has been described in other fungi such as Serendipita indica that plant IAA levels have little or no effect on the beneficial fungus-mediated growth promotion, as the plant is very sensitive to changes in IAA concentration and a slight increase in this phytohormone, rather than stimulate, can limit growth [30]. It is well known that additional Trichoderma metabolites and proteins are involved in the regulation of IAA signals in the plant, leading to root hair growth and increased root mass development [31-33]. This evidence seems to indicate that rather than a major function in root morphogenesis, IAA and the other phytohormones of fungal origin play a role in interconnecting plant development and defense responses as a component of the complex Trichoderma-regulated phytohormone networking in plants [12,13].

To further complicate the understanding of this issue, ethylene (ET) is a phytohormone which regulates plant growth, development, and senescence, and it is well established that low ET concentrations in the root zone correspond to higher shoot growth [34]; therefore, limiting the levels of ET serves to increase agricultural production. A strategy followed by many rhizospheric microorganisms to favor plants consists of reducing the concentration of 1-aminocyclopropane-1-carboxylic acid (ACC), the precursor molecule of ET, by means of the ability to produce the enzyme ACC deaminase (ACCD). Trichoderma strains have the capacity to produce ACCD. This is the case of T. longibrachiatum TL-6, involved in promoting wheat growth and enhancing plant tolerance to salt stress [35], and T. asperelloides (formerly T. asperellum) T203 that by being able to regulate the endogenous ACC levels stimulates root elongation of cucumber [36] and T. asperellum MAP1, which enhanced wheat plant tolerance to waterlogging stress [37].

Wheat is one of the most important crops in the world, providing one-fifth of proteins and calories in human diet, and its extensive production is often subjected to non-irrigation conditions [38]. ROS are key players in the complex signaling network of plant responses to drought stress, so it is essential to maintain ROS at non-toxic levels in a delicate balancing act between ROS production, involving ROS generating enzymes and the unavoidable production of ROS during basic cellular metabolism, and ROS-scavenging pathways [39]. The application of Trichoderma to wheat triggers systemic defense pathways [40] and seems to be a good choice to minimize damage caused by abiotic stresses [35,37], also limiting environmental pollution. There is sufficient evidence to consider that Trichoderma association can help plants in sustaining drought stress by increasing: (i) the expression of antioxidative enzymes that alleviate the damage caused by the accumulation of ROS and modulating the balance of plant's phytohormones [25,41]; (ii) the absorption surface that leads the 
plant to improve water-use efficiency [33]; and (iii) the synthesis of phytohormones and phytohormonal analogues to promote plant performance.

In the present work, we have used four Trichoderma strains of four different species representing the genetic diversity of the genus, in which we analyzed their capacity for wheat root colonization, measured ACCD activity, and production levels of the phytohormones $\mathrm{GA}_{1}, \mathrm{GA}_{4}, \mathrm{ABA}, \mathrm{SA}$, IAA and the CK dihydrozeatin (DHZ), isopenteniladenine (iP) and trans-zeatin (tZ) in medium supplemented or not with Trp. We then analyzed the ability of PDB and PDB-Trp cultures of these strains to favor wheat plants in their growth and their adaptation to grow under water stress. In addition, activities related to the reduction of ROS levels in plants were measured as an indication of good performance of plants inoculated with Trichoderma strains.

\section{Results}

\subsection{Molecular Characterization of Trichoderma Strains}

The identity of the four soil-isolated Trichoderma strains used in this study was confirmed at the species level by analysis of the sequences of ITS1-ITS4 region and a fragment ca. $600 \mathrm{bp}$ in length of tef1 $\alpha$ gene. They had sequences identical to those of ex-type strains or representative species available in databases. They were identified as: T. virens T49, $T$. longibrachiatum T68, T. spirale T75 and T. harzianum T115, and the accession numbers of their sequences in the GenBank are shown in Table 1. These strains showed significant differences in growth and degree of sporulation after culturing in three different culture media (Table 2). Strain T49 showed the highest growth rate when cultivated on PDA, PDATrp and MEA while T75 was the lowest growing on these media. The growth differences observed for T68 between PDA and PDA-Trp indicate that the addition of Trp negatively affected the growth of this strain. The effect of culture medium was also observed on the sporulation degree, with T75 being the strain that significantly showed the lowest values on PDA or PDA-Trp, and T49 the highest on MEA.

Table 1. Source, origin and accession numbers of Trichoderma strains included in this study.

\begin{tabular}{ccccc}
\hline Strain & Identified as & Source & Origin & $\begin{array}{c}\text { GenBank } \\
\text { NumbersITS//tef1 } \boldsymbol{\alpha}\end{array}$ \\
\hline T49 & T. virens & soil & Brazil & MZ312097//MZ346026 \\
T68 & T. longibrachiatum & soil & Brazil & MZ311298//MZ346027 \\
T75 & T. spirale & soil & Spain & MZ311299//MZ346028 \\
T115 & T. harzianum & soil & Philippines & MZ313912//MZ346029 \\
\hline
\end{tabular}

Table 2. Colony growth of Trichoderma strains, expressed in cm, on PDA, PDA-Trp and MEA after $48 \mathrm{~h}$ at $28^{\circ} \mathrm{C}$, and sporulation rate (spore $/ \mathrm{mL}$ ) measured at 10 days of incubation.

\begin{tabular}{ccccccc}
\hline \multirow{2}{*}{ Strain } & \multicolumn{3}{c}{ Growth Rate } & \multicolumn{3}{c}{ Spores Produced } \\
\cline { 2 - 7 } & PDA & PDA-Trp & MEA & PDA & PDA-Trp & MEA \\
\hline T49 & $7.1 \mathrm{a}$ & $6.9 \mathrm{a}$ & $7.0 \mathrm{a}$ & $2.5 \times 10^{8} \mathrm{a}$ & $4.1 \times 10^{8} \mathrm{~b}$ & $1.46 \times 10^{8} \mathrm{a}$ \\
T68 & $7.0 \mathrm{a}$ & $6.3 \mathrm{~b}$ & $4.7 \mathrm{c}$ & $2.4 \times 10^{8} \mathrm{a}$ & $4.2 \times 10^{8} \mathrm{~b}$ & $6.2 \times 10^{7} \mathrm{~b}$ \\
T75 & $4.1 \mathrm{c}$ & $4.0 \mathrm{~d}$ & $3.6 \mathrm{~d}$ & $6.8 \times 10^{6} \mathrm{~b}$ & $7.7 \times 10^{5} \mathrm{c}$ & $1.2 \times 10^{7} \mathrm{~b}$ \\
T115 & $5.4 \mathrm{~b}$ & $5.4 \mathrm{c}$ & $5.4 \mathrm{~b}$ & $4.0 \times 10^{8} \mathrm{a}$ & $7.7 \times 10^{8} \mathrm{a}$ & $4.9 \times 10^{7} \mathrm{~b}$ \\
\hline
\end{tabular}

Data are calculated from $n=4$ replicates per condition. Values in the same column with different letters are significantly different according to one-way analysis of variance (ANOVA) followed by Tukey's test at the 0.05 alpha-level of confidence.

\subsection{Differences in Colonization of Roots of Wheat Seedlings by Trichoderma Strains}

In order to perform a comparative analysis of the wheat root colonization ability among the four Trichoderma strains, we determined the proportion of fungal DNA vs. plant DNA from qPCR data in 10-day-old seedling roots at $42 \mathrm{~h}$ after fungal inoculation. As 
shown in Table 3, strains T49, T75 and T115 colonized the roots, with the highest rates for T49 and T75 $(p<0.05)$, while T68 showed no colonization.

Table 3. Colonization of wheat roots by Trichoderma strains (T. virens T49, T. longibrachiatum T68, $T$ spirale $\mathrm{T} 75$ and T. harzianum T115) *.

\begin{tabular}{cccccccccc}
\hline \multirow{2}{*}{ Strains } & \multicolumn{3}{c}{ Trichoderma Actin } & \multicolumn{5}{c}{ Wheat Ctin } & \multirow{2}{*}{ Ratio **** } \\
\cline { 2 - 8 } & Ct & SD & Qty ${ }^{* *}$ & SD & Ct & SD & Qty ** & SD & \\
\hline T49 & 18.06 & 0.07 & 3.08 & 0.80 & 22.85 & 0.11 & 2.47 & 0.73 & $1.39 \pm 0.71 \mathrm{a}$ \\
T68 & 19.40 & 0.04 & 0.16 & 0.18 & 22.36 & 0.30 & 2.99 & 1.14 & $0.04 \pm 0.04 \mathrm{c}$ \\
T75 & 17.39 & 0.02 & 5.13 & 0.72 & 21.95 & 0.09 & 4.70 & 0.14 & $1.09 \pm 0.13 \mathrm{ab}$ \\
T115 & 18.66 & 0.10 & 2.74 & 0.54 & 21.89 & 0.15 & 4.22 & 0.45 & $0.65 \pm 0.11 \mathrm{~b}$ \\
\hline
\end{tabular}

${ }^{*}$ Fungal DNA present on wheat roots $42 \mathrm{~h}$ after the inoculation was quantified by qPCR. $\mathrm{Ct}$, threshold cycle and SD, standard deviation. ${ }^{* *}$ Quantity of Trichoderma DNA (ng) referred to Trichoderma actin gene. ${ }^{* * *}$ Quantity of wheat DNA (ng) referred to wheat actin gene. ${ }^{* * * *}$ Proportion of fungal DNA vs. plant DNA. Data are calculated from $n=4$ replicates per strain. Values in the same column with different letters are significantly different according to one-way analysis of variance (ANOVA) followed by Tukey's test at the 0.05 alpha-level of confidence.

\subsection{Differences in ACCD Activity and Phytohormonal Profiles in Trichoderma Strains}

The ACCD activity was calculated for all four strains after growing them for four days in synthetic minimal medium. Strain T115 showed significantly higher specific ACCD activity (1.8 mmol of $\alpha$-ketobutyrate per $\mathrm{mg}$ of protein) compared to that of the other three strains ( 0.09 to $0.20 \mathrm{mmol} \alpha$-ketobutyrate per $\mathrm{mg}$ of protein) (Tukey test at $p<0.05$ ), which showed no significant differences between them.

The production of eight phytohormones by the four Trichoderma strains was measured in PDB medium with and without Trp. Since the PDB medium is composed of plant material, uninoculated media were used as controls. Under these two conditions, a comparative analysis of the production profiles of $\mathrm{GA}_{4}, \mathrm{GA}_{1}, \mathrm{ABA}, \mathrm{SA}, \mathrm{IAA}, \mathrm{DHZ}$, iP and $\mathrm{tZ}$ by strains T49, T68, T75 and T115 is shown in Figure 1. When compared to the control conditions of each culture medium in a one-way ANOVA, not all Trichoderma strains exhibited production of the eight phytohormones in both media. There was an effect of the variable "strain" $(p<0.001)$ and variable "medium" $(p<0.001)$, and their combination on the production of seven of the phytohormones investigated, according to a two-way ANOVA $(p<0.001)$.

Particularly, the CK iP was the only one that showed no significant effect for the combination of the two variables. T. virens T49 significantly exhibited the highest levels of $\mathrm{GA}_{4}$ in both media, being much higher in PDB-Trp $(p<0.001)$. Considering the phytohormone production profiles as a whole T. longibrachiatum T68 did not stand out for any of them. In addition, $\mathrm{GA}_{4}$ levels were lower for this strain than those detected in its controls, which would be indicative of the metabolization of this molecule present in the medium. Similar behavior was observed only for $\mathrm{GA}_{1}$ with strains T75 and T115 in PDB-Trp medium. T. spirale T75 showed the highest production levels of SA, IAA and CK. The biosynthesis of SA and CK by this strain did not respond to the addition of Trp to the culture medium. However, strain T75 in PDB-Trp increased IAA levels by about 80 times. On the contrary, strain T49 showed higher levels of IAA production in PDB than in PDB-Trp. T. harzianum T115 was the strain in which the levels of $\mathrm{GA}_{1}$ and ABA production in PDB were significantly the highest. 


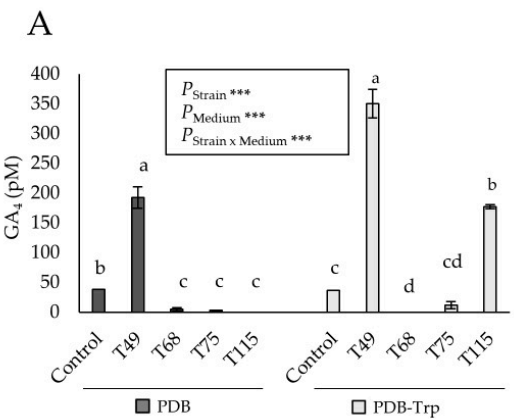

C
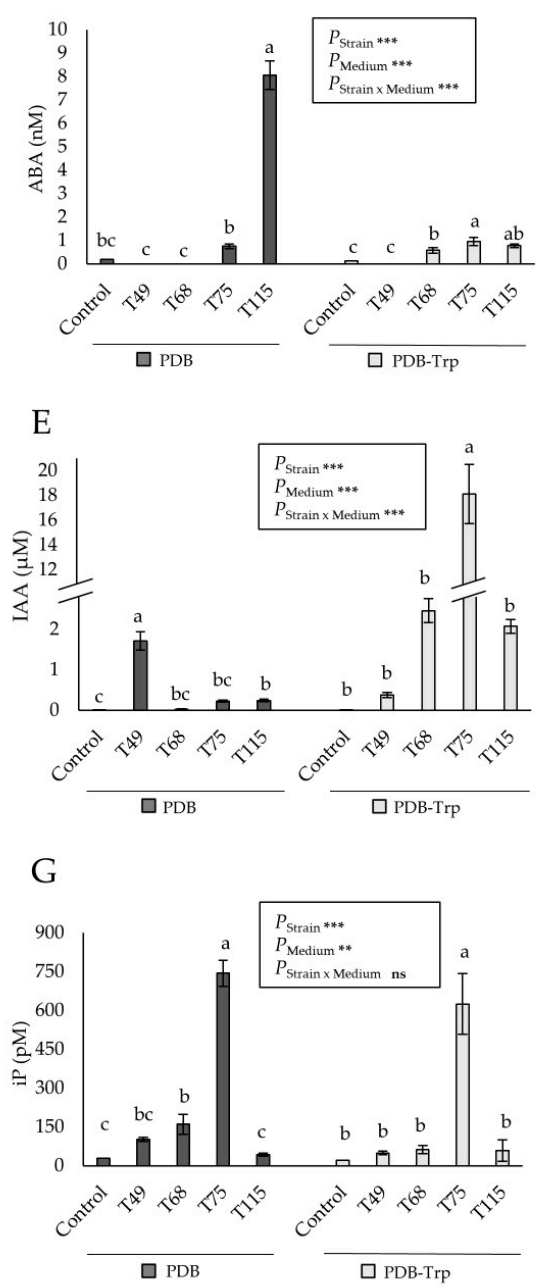

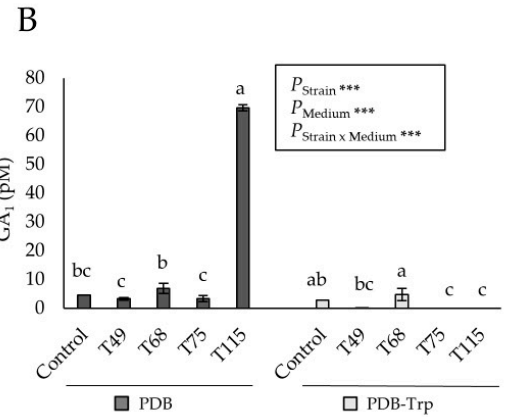

$\mathrm{D}$
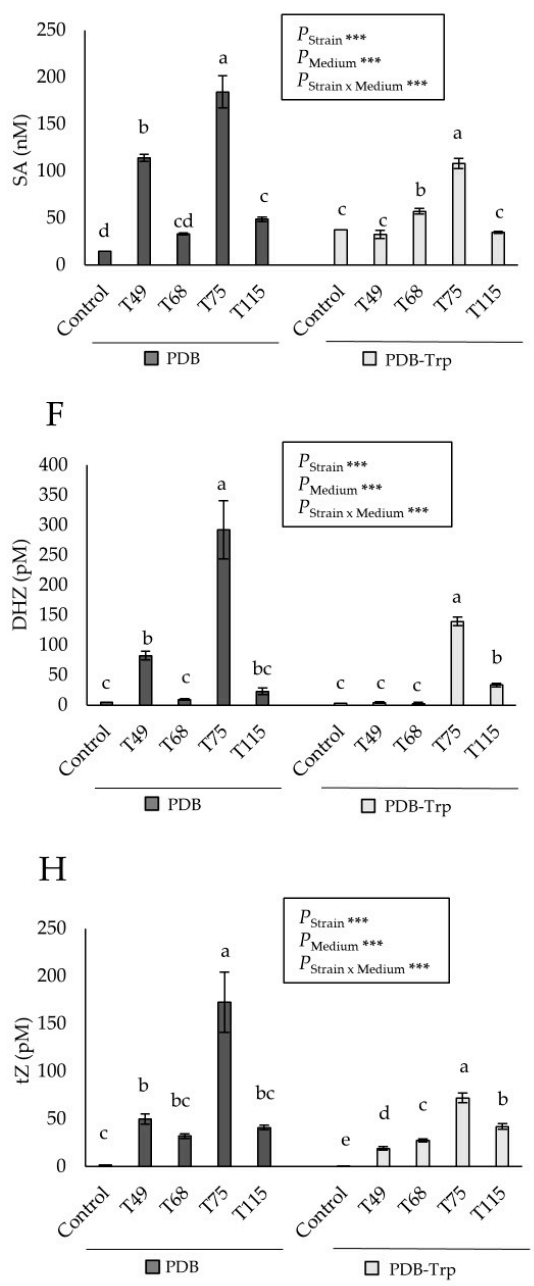

Figure 1. Phytohormone production in 4-days PDB and PDB-tryptophan (Trp) cultures by four Trichoderma strains (T. virens T49, T. longibrachiatum T68, T spirale T75 and T. harzianum T115) compared to their respective PDB and PDB-Trp media controls. (A) Gibberellin $4\left(\mathrm{GA}_{4}\right)$, (B) gibberellin $1 \mathrm{GA}_{1},(\mathbf{C})$ abscisic acid (ABA), (D) salicylic acid (SA), (E) indole-3-acetic acid (IAA), (F) cytokinin dihydrozeatin (DHZ), (G) cytokinin isopenteniladenine (iP), and (H) cytokinin trans-zeatin (tZ). Data are calculated from $n=3$ replicates per strain and culture medium. For each phytohormone and culture medium, different letters above the bars indicate significant differences according to one-way analysis of variance (ANOVA) followed by Tukey's test at the 0.05 alpha-level of confidence. For each phytohormone, significant effects were determined by a two-way ANOVA for Trichoderma strain, culture medium and the combination strain per culture medium $\left(^{* * *}: p<0.001{ }^{* * *} p<0.01\right.$; ns: no statistical differences). 


\subsection{The Effect of Trichoderma Strains on Wheat Plants under Drought Stress}

Greenhouse-grown wheat plants were used to evaluate the effect of PDB and PDB-Trp cultures of the four Trichoderma strains when they were applied to the plant substrate. Plant fresh and dry weight and conductance parameters were measured after 30 days of growth under optimal irrigation and $1 / 3$ of the watering applied during the third and fourth weeks (water stress) (Tables 4 and 5). Representative phenotypes observed in wheat plants treated with the different Trichoderma cultures and irrigation regimes are shown in Figure 2. In a broad sense, the one-way ANOVA results showed the existence of significance for the factors "strain" $(p<0.001)$, "culture medium" $(p<0.001)$ and "stress" $(p<0.001)$. Two different plant responses were observed for Trichoderma cultures from both PDB and PDBTrp media. Therefore, plants treated with T68 and T75 PDB cultures significantly showed the lowest fresh and dry weight compared to the other treatments under optimal irrigation conditions (Table 4). On the other hand, under water stress conditions, plants treated with PDB cultures of T49 and T115 had significantly the highest weights, with an increase of ca. $100 \%$. Regarding conductance values, wheat plants showed significantly higher numbers with T49 and T115 PDB cultures under optimal irrigation conditions, whereas the control presented a significant reduction compared to any of the four Trichoderma strains applied under water stress.

Table 4. Effect of 4-days PDB cultures of Trichoderma strains on mean fresh and dry weight and conductance values of 30-day-old wheat plants grown in greenhouse with optimal irrigation and water stress conditions $(1 / 3$ in the last two weeks).

\begin{tabular}{|c|c|c|c|c|c|c|}
\hline \multirow[b]{2}{*}{ Treatment } & \multicolumn{2}{|c|}{ Fresh Weight (g) } & \multicolumn{2}{|c|}{ Dry Weight (g) } & \multicolumn{2}{|c|}{ gs $\left(\mathrm{mol} \mathrm{H}_{2} \mathrm{O} \mathrm{m}^{-2} \mathrm{~s}^{-1}\right)$} \\
\hline & $\begin{array}{c}\text { Optimal } \\
\text { Irrigation }\end{array}$ & $\begin{array}{l}\text { Water } \\
\text { Stress }\end{array}$ & $\begin{array}{c}\text { Optimal } \\
\text { Irrigation }\end{array}$ & $\begin{array}{l}\text { Water } \\
\text { Stress }\end{array}$ & $\begin{array}{l}\text { Optimal } \\
\text { Irrigation }\end{array}$ & $\begin{array}{l}\text { Water } \\
\text { Stress }\end{array}$ \\
\hline Control & $1.13 \mathrm{a}$ & $0.39 \mathrm{~b}$ & $0.22 \mathrm{a}$ & $0.10 \mathrm{~b}$ & $0.166 \mathrm{~b}$ & $0.006 \mathrm{~b}$ \\
\hline $\mathrm{T} 49$ & $1.09 \mathrm{a}$ & $0.82 \mathrm{a}$ & $0.21 \mathrm{a}$ & $0.22 \mathrm{a}$ & $0.278 \mathrm{a}$ & $0.089 \mathrm{a}$ \\
\hline $\mathrm{T} 68$ & $0.51 \mathrm{~b}$ & $0.35 \mathrm{~b}$ & $0.11 \mathrm{~b}$ & $0.07 \mathrm{~b}$ & $0.108 \mathrm{~b}$ & $0.110 \mathrm{a}$ \\
\hline $\mathrm{T} 75$ & $0.35 \mathrm{~b}$ & $0.41 \mathrm{~b}$ & $0.10 \mathrm{~b}$ & $0.08 \mathrm{~b}$ & $0.139 \mathrm{~b}$ & $0.132 \mathrm{a}$ \\
\hline T115 & $0.93 \mathrm{a}$ & $0.76 \mathrm{a}$ & $0.20 \mathrm{a}$ & $0.17 \mathrm{a}$ & $0.234 \mathrm{a}$ & $0.100 \mathrm{a}$ \\
\hline
\end{tabular}

Data are calculated from $n=10$ replicates per treatment and condition. Values in the same column with different letters are significantly different according to one-way analysis of variance (ANOVA) followed by Tukey's test at the 0.05 alpha-level of confidence.

Table 5. Effect of 4-days PDB-Trp cultures of Trichoderma strains on mean fresh and dry weight and conductance values of 30-day-old wheat plants grown in greenhouse with optimal irrigation and water stress conditions $(1 / 3$ in the last two weeks).

\begin{tabular}{ccccccc}
\hline \multirow{2}{*}{ Treatment } & \multicolumn{2}{c}{ Fresh Weight $(\mathbf{g})$} & \multicolumn{2}{c}{ Dry Weight $(\mathbf{g})$} & \multicolumn{2}{c}{ gs $\left(\mathbf{m o l ~ H}_{\mathbf{2}} \mathbf{O ~ m}^{-\mathbf{2}} \mathbf{~ s}^{-\mathbf{1}}\right)$} \\
\cline { 2 - 7 } & $\begin{array}{c}\text { Optimal } \\
\text { Irrigation }\end{array}$ & $\begin{array}{c}\text { Water } \\
\text { Stress }\end{array}$ & $\begin{array}{c}\text { Optimal } \\
\text { Irrigation }\end{array}$ & $\begin{array}{c}\text { Water } \\
\text { Stress }\end{array}$ & $\begin{array}{c}\text { Optimal } \\
\text { Irrigation }\end{array}$ & $\begin{array}{c}\text { Water } \\
\text { Stress }\end{array}$ \\
\hline Control & $1.26 \mathrm{a}$ & $0.82 \mathrm{a}$ & $0.20 \mathrm{a}$ & $0.19 \mathrm{a}$ & $0.189 \mathrm{ab}$ & $0.157 \mathrm{a}$ \\
T49 & $1.32 \mathrm{a}$ & $0.67 \mathrm{a}$ & $0.23 \mathrm{a}$ & $0.22 \mathrm{a}$ & $0.213 \mathrm{a}$ & $0.188 \mathrm{a}$ \\
T68 & $0.68 \mathrm{~b}$ & $0.52 \mathrm{a}$ & $0.12 \mathrm{~b}$ & $0.11 \mathrm{~b}$ & $0.147 \mathrm{~b}$ & $0.165 \mathrm{a}$ \\
T75 & $0.55 \mathrm{~b}$ & $0.61 \mathrm{a}$ & $0.11 \mathrm{~b}$ & $0.12 \mathrm{~b}$ & $0.150 \mathrm{~b}$ & $0.161 \mathrm{a}$ \\
T115 & $1.27 \mathrm{a}$ & $0.74 \mathrm{a}$ & $0.24 \mathrm{a}$ & $0.21 \mathrm{a}$ & $0.162 \mathrm{ab}$ & $0.108 \mathrm{a}$ \\
\hline
\end{tabular}

Data are calculated from $n=10$ replicates per treatment and condition. Different letters indicate significant differences within each column according to one-way analysis of variance (ANOVA) followed by Tukey's test at the 0.05 alpha-level of confidence. 
A

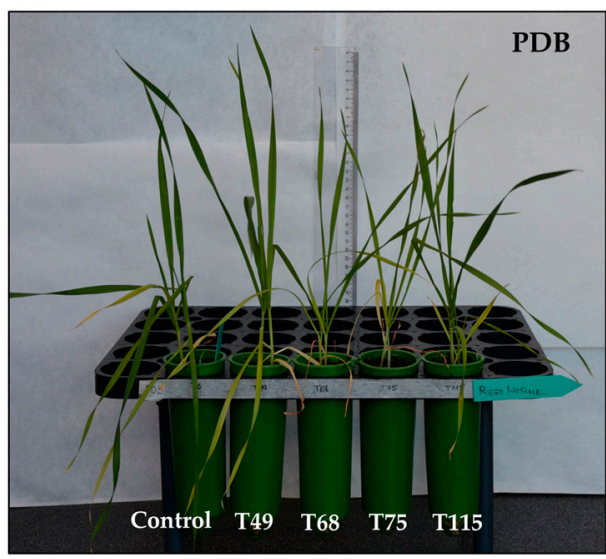

Optimal irrigation

C

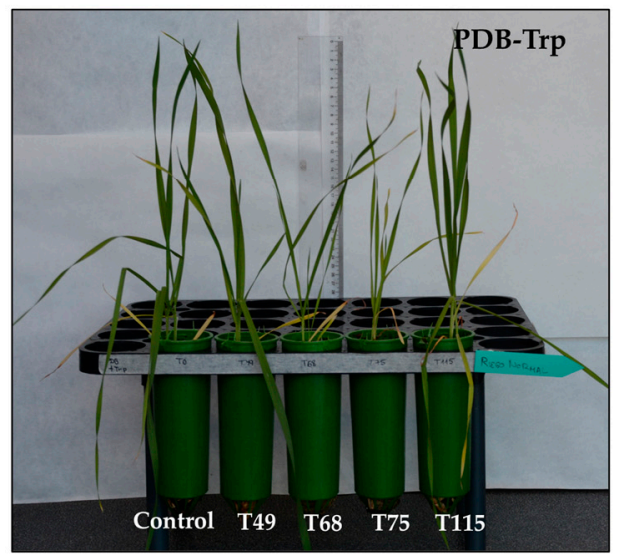

Optimal irrigation

\section{B}

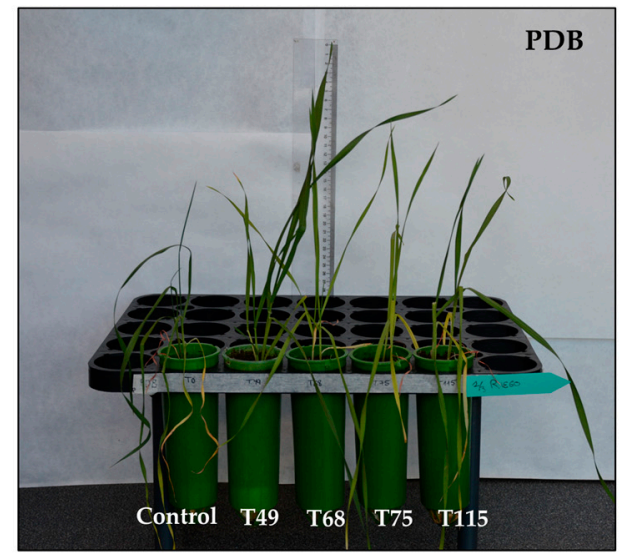

Water stress

D

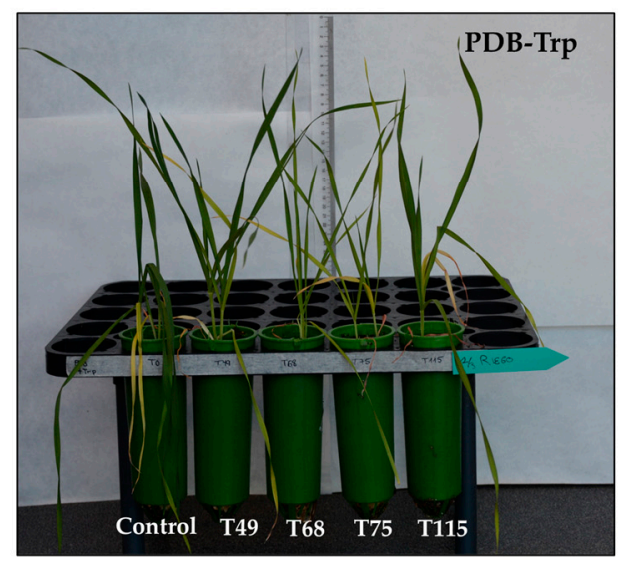

Water stress

Figure 2. Wheat plants from untreated (control) or treated with Trichoderma (T. virens T49, T. longibrachiatum T68, T spirale T75 and T. harzianum T115) strains subjected to different irrigation regimes. (A) Four-days PDB Trichoderma cultures were applied to the plant growth substrate or PDB (control) under optimal irrigation. (B) The same under water stress $(1 / 3$ of the watering applied during the third and fourth weeks) condition. (C) four-days PDB-tryptophan (Trp) Trichoderma cultures were applied to the substrate of plant growth or PDB-Trp (control) under optimal irrigation. (D) The same under water stress (1/3 of the watering applied during the third and fourth weeks) condition. Photographs were taken when plants were 30 days old.

In a similar way, wheat plants treated with T68 and T75 PDB-Trp cultures had significantly lower fresh and dry weight values than control plants or those treated with T49 and T115 PDB-Trp cultures under optimal irrigation conditions (Table 5). However, no differences in weight and conductance values under water stress were observed among treatments with the sole exception of those plants treated with T68 or T75 PDB-Trp cultures, which gave significantly lower dry weight values (Table 5). A two-way ANOVA for dry weight data showed significance for "culture medium" $\times$ "stress" $(p<0.05)$; and for conductance data, all combinations ("strain" $\times$ "culture medium", "strain" $\times$ "stress", "culture medium" $\times$ "stress"; $p<0.001)$ were significant. Additionally, a three-way ANOVA showed significance for the combination "strain" $\times$ "culture medium" $\times$ "stress" for fresh and dry weight $(p<0.05)$ and for conductance $(p<0.01)$.

Endogenous $\mathrm{H}_{2} \mathrm{O}_{2}$ content in wheat leaf from 30-day-old plants did not show variation in unstressed plants, neither in the control nor with Trichoderma regardless of the presence of Trp in the medium to grow the fungus (Figure 3). Water stress control plants from the PDB condition showed a significant increase in $\mathrm{H}_{2} \mathrm{O}_{2}$ content compared to those challenged with Trichoderma. However, PDB-Trp condition stressed control plants showed lower levels 
of $\mathrm{H}_{2} \mathrm{O}_{2}$ than plants treated with Trichoderma cultures, which in turn were significantly different, with the highest levels for the T115 treatment. The two-way ANOVA showed significance of the three considered factors and their pairwise combinations $(p<0.01)$ with the only exception of "culture medium" $\times$ "stress", while the three-way ANOVA was significant for the three factors together $(p<0.01)$.
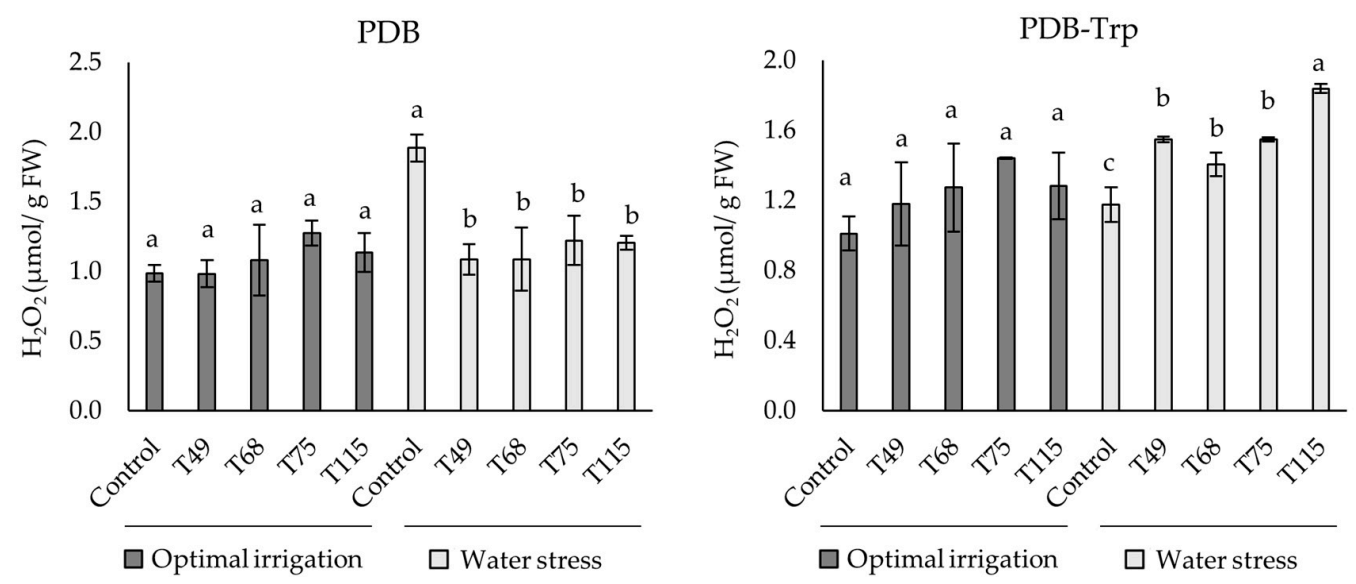

Figure 3. Effect of T. virens T49, T. longibrachiatum T68, T spirale T75 and T. harzianum T115 treatments from 4-days PDB and PDB-tryptophan (Trp) cultures on $\mathrm{H}_{2} \mathrm{O}_{2}$ content in wheat plant leaf grown under optimal irrigation and water stress $(1 / 3$ of the watering applied during the third and fourth weeks) conditions. Values are expressed in $\mu$ moles of $\mathrm{H}_{2} \mathrm{O}_{2}$ per g of leaf fresh weight (FW). Data are calculated from $n=4$ replicates for each strain, culture medium and plant growth condition. For each fungal culture medium and plant growth conditions, different letters above the bars indicate significant differences according to one-way analysis of variance (ANOVA) followed by Tukey's test at the 0.05 alpha-level of confidence.

The values calculated for three antioxidant enzymes in wheat plants are shown in Figure 4. Compared to the respective controls, in the absence of water stress and when Trp was not added to the fungal culture medium, the application of Trichoderma cultures resulted in significant SOD activity increase, except for the T115 treatment. Trichoderma application significantly decreased POD without changing CAT activity. Unstressed plants treated with Trichoderma PDB-Trp cultures increased SOD activity compared to the control. However, POD activity only decreased significantly in T115-treated plants, with CAT activity being lower than that of the control in all cases. Differences were also observed among Trichoderma treatments as the decrease in CAT activity was significantly lower in plants challenged with T68. Under the condition of water stress, no significant differences were detected in SOD, POD and CAT activities of plants subjected to any of the PDB-Trp treatments compared to the control. However, in absence of Trp in Trichoderma cultures, the stressed plants responded to Trichoderma by lowering POD and CAT activities, and only strain T49 and T68 were able to significantly rise SOD activity. ANOVA values indicate that the factor "strain" had significance in the three tested enzymatic activities of plants $(p<0.001)$, while the factor "stress" had significance in SOD $(p<0.001)$ and CAT $(p<0.05)$, and factor "culture medium" in SOD $(p<0.001)$ and POD $(p<0.05)$. 


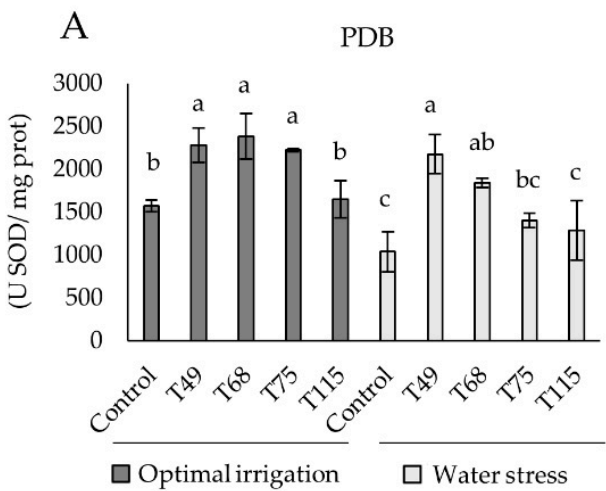

$$
\text { B }
$$
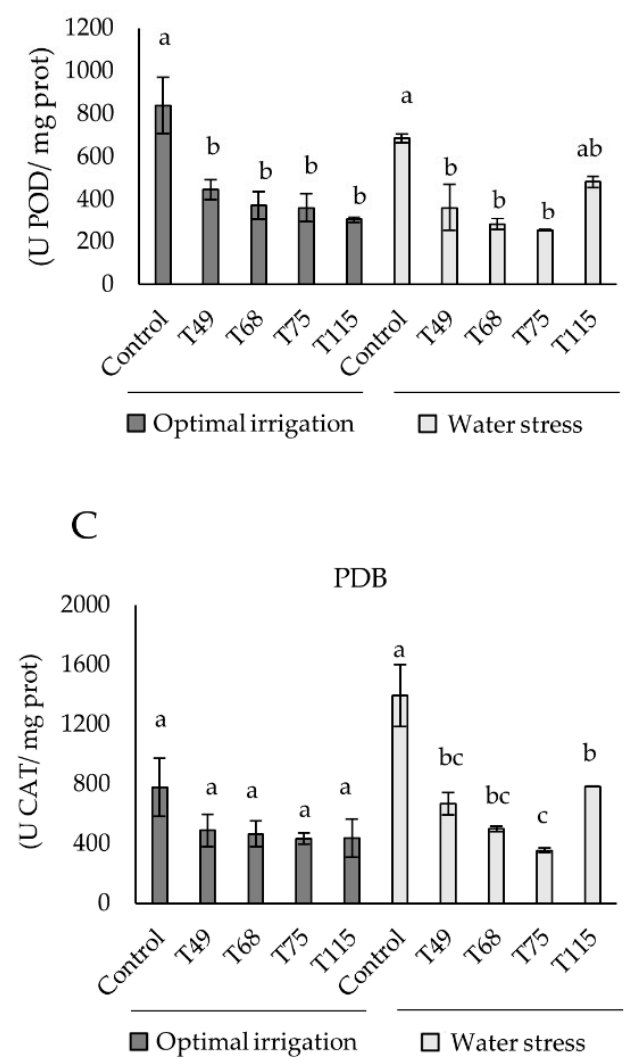

PDB-Trp

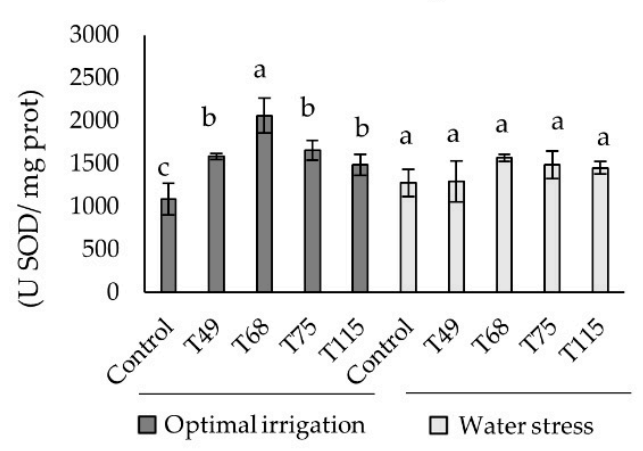

PDB-Trp

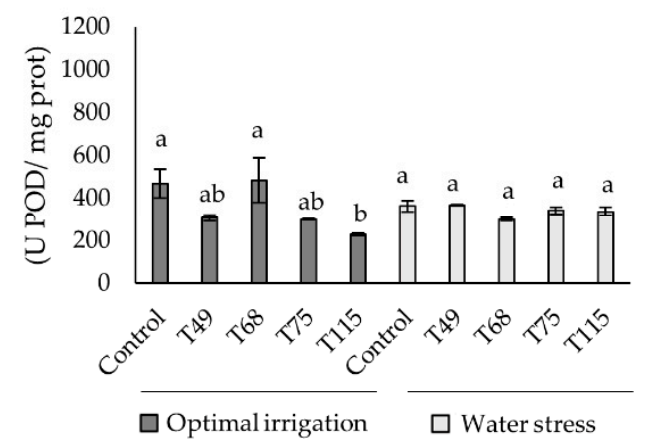

PDB-Trp

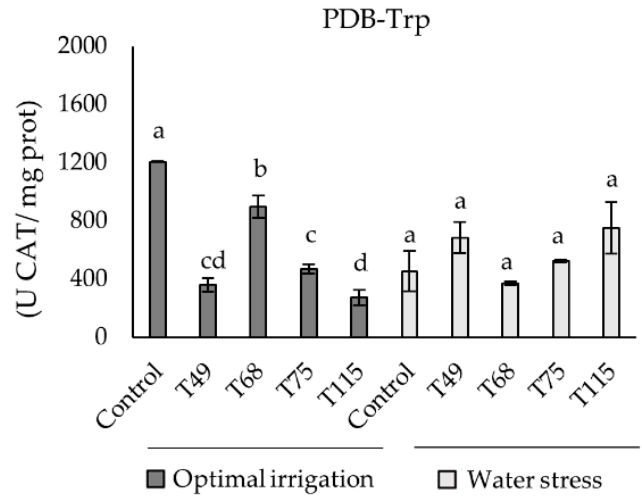

Figure 4. Effect of Trichoderma strain (T. virens T49, T. longibrachiatum T68, T spirale T75 and T. harzianum T115) treatments from 4-days PDB and PDB-tryptophan (Trp) cultures on (A) SOD, (B) POD and (C) CAT activities of wheat plants grown under optimal irrigation and water stress $(1 / 3$ of the watering applied during the third and fourth weeks) conditions. Data are calculated from $n=4$ replicates for each strain, culture medium and plant growth condition. For each fungal culture medium and plant growth condition, different letters above the bars indicate significant differences according to one-way analysis of variance (ANOVA) followed by Tukey's test at the 0.05 alpha-level of confidence. SOD: superoxide dismutase, POD: peroxidase, and CAT: catalase.

\section{Discussion}

Trichoderma is a very complex fungal genus that includes nearly 400 species [42]. The practical application of Trichoderma needs a correct molecular characterization as the biocontrol, biostimulation and other beneficial effects to plants should not be considered in broad terms, but at the level of strain. We have included in our study four strains belonging to four phylogenetically distant species to explore their behavior regarding 
how they promote growth and favor water-stressed wheat plants. Modern Trichoderma taxonomy suggests the analysis of three DNA barcodes (ITS, tef1 and rpb2) [42], and we have achieved unambiguous species identification by ITS1-ITS4 and $600 \mathrm{bp}$ in length of tef1 $\alpha$ gene sequencing. Two out of four strains identified belong to T. harzianum and T. virens, two species widely used as biocontrol agents in commercial practice $[43,44]$. The other two strains belong to species less used in biological control, although there is recent work on the efficacy of T. spirale and T. longibrachiatum in the control of plant pathogenic fungi $[45,46]$.

Our study has been focused on the abilities of these strains to stimulate the growth of wheat plants and alleviate them from water stress. Root colonization ability is often a criterion for selecting Trichoderma strains beneficial to plants [12], and we found that wheat was not a host for strain T68. An important and little studied aspect of Trichoderma is the capacity to produce phytohormones that may be involved in plant interactions. Depending on the strain of Trichoderma and the composition of the culture medium, with or without addition of Trp, or the combination of both, the production of phytohormones was affected. The observed differences in phytohormone production could be affected by the degree of growth of the different strains. However, strain T68 showed good growth and sporulation performances on PDA and PDA-Trp and did not stand out in the production of any of the eight phytohormones tested in PDB and PDB-Trp. PDB has been used because it is a common medium for Trichoderma growth and because the production of IAA has been described in this medium supplemented with Trp [16]. As PDB contains molecules of plant origin, the uninoculated medium has been used as a control, with and without Trp addition, to subtract possible phytohormones already present in the fungal culture media. Although Trp-containing media seem to favor the production of IAA, this is not a rule, as strain T49 showed a behavior contrary to the other three Trichoderma strains. T49 and T115 were the only strains that produced $\mathrm{GA}_{4}$ and $\mathrm{GA}_{1}$, respectively, in medium not supplemented with Trp. However, the addition of Trp to the growth medium of the fungus induced $\mathrm{GA}_{4}$, but not $\mathrm{GA}_{1}$, production in both strains. Production of $\mathrm{GA}_{3}$ has been described in T. harzianum, and accumulation of this phytohormone in combination with IAA has been related to plant growth promotion $[15,19]$. The production of gibberellic acid by Trichoderma also cooperates with IAA and ACCD in the modulation of defense responses in wheat seedlings [18]. Production of $\mathrm{GA}_{1}$ and $\mathrm{GA}_{4}$ have been described in other fungi such as Phoma, Penicillium and Aspergillus as plant growth promoters under stress conditions $[47,48]$. In our case, we have seen that the production profiles of $\mathrm{GA}_{1}$ and $\mathrm{GA}_{4}$ are antagonistic, and in the strains that produce them, T49 and T115, their biosynthesis seems to be compensated. It is well known the antagonistic regulation of GA and ABA in plants [49], and this also occurs in Trichoderma for $\mathrm{GA}_{4}$ and ABA production. However, this was not the case of $\mathrm{GA}_{1}$, as strain T115 reached in PDB the highest levels of this phytohormone and ABA simultaneously. Regarding CK, it has been described that their production in fungi is related to hyphal growth and branching, and their accumulation allows better adaptation to stress and colonization of the roots, although the effect on fungal growth is made in a dose-dependent manner [3]. T. spirale T75 produced the highest amount of the three $\mathrm{CK}$ analyzed, $\mathrm{DHZ}, \mathrm{iP}$ and $\mathrm{tZ}$, in the two media used and this was accompanied by the slowest significant growth on PDA and PDA-Trp. As seen in plants [1], this strain showed the typical IAA-CK antagonism when cultured in PDB. However, strain T75 showed the highest IAA and CK production values in PDB-Trp. It should be noted that the production of IAA by strain T75 in PDB-Trp was particularly high and that the trend in all strains was that the addition of Trp reduced the CK levels.

Trichoderma can manipulate the phytohormone regulatory network decreasing the ET precursor ACC through the ACCD activity [12,36]. The four Trichoderma strains exhibited ACCD activity although strain T115 showed 20 times more activity than the other three under identical growth conditions in a synthetic medium. These results are also a consequence of working with strains from genetically very distant species, given the great diversity that exists within the Trichoderma genus [50]. Trichoderma ACCD has also been described as a mechanism in enhancing wheat tolerance to salt stress [35] and wa- 
terlogging [37]. Our study has included the application of Trichoderma to wheat plants to analyze the effect on growth and tolerance to water stress. The greenhouse assay was conducted using mycelium plus culture supernatant of Trichoderma to inoculate the substrate where wheat plants were grown, and it is therefore difficult to assess the role of Trichoderma phytohormones in wheat plant responses. Under optimal irrigation conditions, none of the treatments with Trichoderma appeared to promote the growth of wheat plants. Moreover, two of the strains, T68 and T75, performed worse than the PDB and PDB-Trp control plants (Figure 2). Perhaps the smaller size and weight of plants compared to their controls (Tables 4 and 5) may be because these two Trichoderma strains show no GA 1 and $\mathrm{GA}_{4}$ production. It is noteworthy that strain T75, which produced as indicated above the highest concentrations of IAA in PDB-Trp, did not promote plant growth, which would indicate that fungal IAA contributes to the total concentrations of this phytohormone, but it is not the major player in root development as plant IAA does. The high levels of SA and CK reached by this strain (Figure 2) could be the cause of the phenotype observed in T75-treated plants. Since strain T68 was unable to colonize the wheat root, it may be releasing some other metabolites that could limit the growth of the plant. PDB cultures from strains T49 and T115, those producing maximum amounts of $\mathrm{GA}_{4}$, and $\mathrm{GA}_{1}$ and ACCD activity, respectively, were the ones that best increased plant tolerance to water stress, also being the ones that provided higher conductance and weight values in plants (Table 4). The importance of selecting a suitable strain of Trichoderma is a key point in this type of study, as it has been observed that the colonization of Arabidopsis, tomato and maize roots by T. virens Gv29.8 led to reduced growth of both roots and stems [7,51,52]. Nevertheless, plants treated with PDB cultures of strains T68 and T75 did not show increased growth but did show high conductance (Table 4) and a water stress tolerance phenotype compared with PDB control plants (Figure 2). The significant increases in conductance that we observed in plants from the Trichoderma PDB treatments compared to their control under water stress conditions agree with previous reports indicating that Trichoderma can ameliorate the conductance decline in drought stressed plants [26,53].

Plants treated with Trichoderma PDB cultures under water stress conditions significantly decreased the $\mathrm{H}_{2} \mathrm{O}_{2}$ content compared to the control, although no differences were detected under optimal irrigation condition. This result is in line with what has been described in maize treated with T. atroviride under drought stress [27]. In the present study, all Trichoderma strains were able to produce to a greater or lesser extent SA (Figure 2), this phytohormone being very important in the establishment of a plant oxidative burst in response to stress, but also in the upregulation of antioxidant metabolism [13]. The antioxidant level in plant was analyzed by measuring SOD, POD and CAT activities. In a broad sense and as expected, Trichoderma increased the SOD antioxidant activity of the plants under water stress conditions. These results would agree with those reported in stressed or infected tomato plants inoculated with Trichoderma [25,54]. Like in maize inoculated with $T$. harzianum under salt stress [55], we have also seen that Trichoderma application decreased POD and CAT activities under water deficit conditions. Considering the profiles observed for the three enzyme activities in wheat plants treated with Trichoderma PDB cultures, it seems that the effect of Trichoderma prevails over the stress condition in driving the plant's antioxidant machinery. The addition of Trp to Trichoderma cultures did not appear to modify plant antioxidant enzyme profiles, upregulation of SOD and downregulation of CAT, under non-stressed conditions. However, stressed plants did not modify their antioxidant activity with respect to the control, and it seems that the Trp effect prevailed over the Trichoderma application. Finally, Trp is shown to play a prominent role in the response of wheat plants to water stress as the PDB-Trp control plants had higher weight and conductance values than the PDB control plants. The phenotype of PDB-Trp control plants agrees with the collapse observed in tomato plants over-stimulated with NPK fertilization and Trichoderma under salt stress [24]. However, the phenotypes of the Trichoderma-treated plants did not appear to be greatly affected by Trp supplementation. 
The production of the phytohormones GAs, ABA, SA, IAA and CKs by Trichoderma species is a strain-specific characteristic and depends on the composition of the culture medium. These differences are a factor to be considered when exploring the beneficial effects of Trichoderma on plants. In this way, the T. virens T49 and T. harzianum T115 cultures were the best performers in alleviating wheat plants from water stress and it was precisely these two strains which exhibited $\mathrm{GA}_{1}$ and IAA, and $\mathrm{GA}_{4}$ and $\mathrm{ABA}$ production, respectively, in media not supplemented with Trp. The present work contributes to highlighting the role that the balance of phytohormone levels, to which Trichoderma contributes with its own production, plays in beneficial plant-Trichoderma interactions. In any case, the growth promotion and plant protection effects of Trichoderma are mechanisms with complex regulation that depends on other Trichoderma traits and not only on the production of phytohormones by this fungus. The results of this work are an example of the usefulness of Trichoderma strains in the protection of crop plants against abiotic stresses.

\section{Materials and Methods}

\subsection{Trichoderma Strains}

Four Trichoderma strains isolated from soil and representing different genotypes were used in this study: T. virens T49, T. longibrachiatum T68, T. spirale T75 and T. harzianum T115 (references of our collection, CIALE, University of Salamanca, Spain). Three out of four strains (T49, T68 and T75) have been included in a previous genetic diversity study and their ITS (internal transcribed spacer) 1 sequence was available [56]. Strains were routinely grown on potato dextrose agar (PDA, Difco Laboratories, Detroit, MI, USA) at $28{ }^{\circ} \mathrm{C}$ in the dark. For long-term storage, the strains were maintained at $-80{ }^{\circ} \mathrm{C}$ in a $30 \%$ glycerol solution.

\subsubsection{Assays of Trichoderma Growth and Sporulation}

For the determination of fungal growth, 5-mm-diameter PDA plugs of fungi were placed at the center of Petri dishes containing PDA, PDA-Trp or malt extract agar (MEA, Difco Laboratories Inc., Detroit, MI, USA) medium, plates were incubated at $28^{\circ} \mathrm{C}$ in the dark, and colony diameters were recorded at two days. After 10 days of incubation at $28^{\circ} \mathrm{C}$, fungal spores were harvested and counted as previously described [23]. For each strain and medium, four replicates were performed.

\subsubsection{Molecular Characterization of Trichoderma Strains}

DNA was obtained from mycelium collected from cultures in potato dextrose broth (PDB, Difco Laboratories Inc.) medium for $48 \mathrm{~h}$ as previously described [57]. The ITS regions of the nuclear rDNA gene cluster, including ITS1 and ITS2 and the 5.8S rDNA gene, and a fragment of the tef1 $\alpha$ gene were amplified with the primer pairs ITS1/ITS4 and EF1-728F/tef1rev, respectively, as described previously [56,58].

PCR products were electrophoresed on $1 \%$ agarose gels, the amplicons were excised from the agarose gels, and DNA purified and sequenced as previously described [58]. The sequences obtained were analyzed considering homology in the NCBI database with ex-type strains and taxonomically established isolates of Trichoderma as references. All sequences obtained in this study have been submitted to GenBank, and their accession numbers are indicated in Table 1.

\subsubsection{Root Colonization Assay}

The quantification of Trichoderma DNA in wheat roots was performed by quantitative PCR (qPCR) as previously described [6,20], with some modifications. Wheat roots were collected from 10-day-old seedlings cultured in 10-mL flasks containing $8 \mathrm{~mL}$ of liquid Murashige and Skoog medium (MS, Duchefa Biochemie BV, Haarlem, Netherlands) supplemented with $1 \%$ sucrose, and inoculated with $10^{5}$ conidial germlings $\mathrm{mL}^{-1}$ of Trichoderma strain or not (control). Three seedlings per flask were used. Trichoderma germlings were obtained from $15 \mathrm{~h}$ cultures in PDB at $28^{\circ} \mathrm{C}$ and $200 \mathrm{rpm}$. After $42 \mathrm{~h}$ of fungal inoculation, the 
wheat roots were collected, washed with sterile water, homogenized under liquid nitrogen, and kept at $-20 \circ \mathrm{C}$ until DNA obtainment. DNA was extracted using the Fast DNA Spin Kit for Soil (MP Biomedical LLC, Irvine, CA, USA). Four independent wheat-Trichoderma strain co-cultures were used for each fungal strain.

qPCR were performed with a Step One Plus thermocycler (Applied Biosystems, Foster City, CA, USA), using KAPA SYBR FAST (Biosystems, Buenos Aires, Argentine) and the previously described primer couples Act-F/ / Act-R ( $5^{\prime}$ ATGGTATGGGTCAGAAGGA- $3^{\prime}$ and $5^{\prime}$ ATGTCAACACGAGCAATGG) [6] and Act-Fw//Act-Rw (5'-TGACCGTATGAGCAAGGAG$3^{\prime} / / 5^{\prime}$-CCAGACACTGTACTTCCTC-3' [40], which amplify a fragment of the actin gene from Trichoderma and wheat, respectively. Reaction mixtures, prepared in triplicate with 1:10 diluted DNA, and PCR conditions were as previously describe [20]. Ct values were calculated and the amount of fungal DNA was estimated using standard curves; and finally values were normalized to the amount of wheat DNA in the samples. Each sample was tested in quadrupled.

\subsubsection{ACCD Activity of Trichoderma Strains}

The ACCD activity of T49, T68, T75 and T115 strains was carried out as previously described $[35,36]$ with some modifications. For each strain, $100 \mu \mathrm{L}$ of spore suspension $\left(1 \times 10^{6}\right.$ spores $\left./ \mathrm{mL}\right)$ were inoculated in $10 \mathrm{~mL}$ of synthetic medium [59], and the cultures grown at $28{ }^{\circ} \mathrm{C}$ and $180 \mathrm{rpm}$ for 4 days. The mycelia were collected, resuspended in $2.5 \mathrm{~mL}$ of Tris buffer $0.1 \mathrm{M}(\mathrm{pH} 8.5)$ and homogenized for $1 \mathrm{~min}$. Toluene $(25 \mu \mathrm{L})$ was added to a $200 \mu \mathrm{L}$ aliquot and vortexed for $30 \mathrm{~s}$, and $20 \mu \mathrm{L}$ of $0.5 \mathrm{M}$ ACC was added (Tris buffer was added in the control). The following steps, including the additions of $\mathrm{HCl}$, 2,4-dinitrophenylhydrazine and $\mathrm{NaOH}$, centrifugations, and the incubation periods of reactions, were as previously described [36]. ACC activity was analyzed quantitatively by measuring the amount of $\alpha$-ketobutyrate produced by the deamination of ACC. $\alpha$ ketobutyrate $(10-200 \mu \mathrm{mol})$ was used for the standard curve and absorbance was measured at $540 \mathrm{~nm}$. ACCD activity was expressed as mmol $\alpha$-ketobutyrate $\mathrm{mg}^{-1}$ protein $\mathrm{h}^{-1}$. The Bradford protein assay was used to measure the protein total concentration in the samples [60] using the BioRad Promega Biotech Ibérica, Alcobendas, Madrid, Spain) reactive. Three independent replicate cultures were analyzed.

\subsubsection{Determination of Phytohormone-like Compounds by Trichoderma}

The strains were grown in $200 \mathrm{~mL}$ of PDB and PDB with $200 \mathrm{mg} / \mathrm{L}$ of tryptophan (PDB-Trp) media at $28^{\circ} \mathrm{C}$ and $200 \mathrm{rpm}$ for 4 days, and culture supernatants were collected by filtration. In parallel, uninoculated PDB and PDB-Trp media were used as controls. The supernatants were lyophilized, the dry weight was measured, and they were kept at $4{ }^{\circ} \mathrm{C}$ until hormones extraction.

Fifty mg (dry weight) of fungal cultures and media supernatant (control) were suspended in $80 \%$ methanol- $1 \%$ acetic acid containing internal standards and mixed by shaking during $60 \mathrm{~min}$ at $4{ }^{\circ} \mathrm{C}$. The extract was kept a $-20{ }^{\circ} \mathrm{C}$ overnight and then centrifuged and the supernatant dried in a vacuum evaporator. The dry residue was dissolved in $1 \%$ acetic acid and passed through the Oasis ${ }^{\circledR}$ HLB (reverse phase) column as previously described [61].

For GA, IAA, ABA and SA quantification, the dried eluate was dissolved in 5\% acetonitrile-1\% acetic acid, and the hormones were separated using an autosampler and reverse phase UHPLC chromatography (2.6 $\mu \mathrm{m}$ Accucore RP-MS column, $100 \mathrm{~mm}$ length $\times 2.1 \mathrm{~mm}$ i.d., ThermoFisher Scientific) with a 5 to $50 \%$ acetonitrile gradient containing $0.05 \%$ acetic acid, at $400 \mu \mathrm{L} / \mathrm{min}$ over $21 \mathrm{~min}$. For CK, the extracts were additionally passed through the Oasis ${ }^{\circledR}$ MCX (cationic exchange) and eluted with $60 \%$ methanol- $5 \% \mathrm{NH}_{4} \mathrm{OH}$ to obtain the basic fraction. The final eluate was dried and dissolved in $5 \%$ acetonitrile- $1 \%$ acetic acid and CK were separated with a 5 to $50 \%$ acetonitrile gradient over $10 \mathrm{~min}$. The hormones were analyzed with a Q-Exactive mass spectrometer (Orbitrap detector, ThermoFisher Scientific, Waltham, MA, USA) by targeted selected ion monitoring (SIM). The concentrations of 
hormones in the extracts were determined using embedded calibration curves and the Xcalibur 4.0 and TraceFinder 4.1 SP1 programs. The internal standards for quantification of each of the different plant hormones were the deuterium-labelled hormones. Three independent replicate flasks were analyzed for each strain and culture medium.

\subsection{Wheat-Trichoderma Greenhouse Assay}

The ability of four Trichoderma strains, T49, T68, T75 and T115, to promote the growth of wheat plants and induce tolerance to water stress was evaluated in a in vivo assay. Wheat (Triticum aestivum L., variety Berdún) seeds were surface disinfected by shaking in $2 \%$ sodium hypochlorite for $20 \mathrm{~min}$ followed by an additional step of $1 \mathrm{~min}$ in $0.1 \mathrm{~N} \mathrm{HCl}$, and then rinsed them five times with sterile water. The seeds stratification was conducted for 3 days at $4{ }^{\circ} \mathrm{C}$. Trichoderma was applied to the plant growth substrate, and Trichoderma cultures were obtained by the inoculation of $0.5 \mathrm{~L}$ flasks containing $250 \mathrm{~mL}$ of PBD or PDB-Trp medium with $1 \times 10^{6}$ spore $/ \mathrm{mL}$ and growing of the strains at $28^{\circ} \mathrm{C}$ and $180 \mathrm{rpm}$ for 4 days. Then, $250 \mathrm{~mL}$ of Trichoderma culture (mycelium and supernatant) were used for inoculating 10 pots.

Surface-disinfected seeds were sown in conical pots (two seeds per pot) of $250 \mathrm{~mL}$ capacity containing as substrate a sterile mixture of commercial (Projar Professional, Comercial Projar SA, Fuente el Saz de Jarama, Spain) peat: vermiculite (3:1). The assay initially included 20 treatments and a total of 200 plants, distributed in two blocks (100 plants per block with 10 replicates per treatment) as follows: five for PDB, four PDB cultures and one PDB medium (control); and five for PDB-Trp, four PDB-Trp cultures and one PDB-Trp medium (control). Plants were maintained in a greenhouse at $22 \pm 4{ }^{\circ} \mathrm{C}$, as previously described [24], and watered as needed for 2 weeks. Thus, plants from the above indicated two blocks were distributed into 2 sub-blocks as follows: (i) plants from PDB cultures with optimal irrigation; (ii) plants from PDB cultures with water stress (1/3 watering during the third and fourth weeks); (iii) plants from PDB-Trp cultures with optimal irrigation; and (iv) plants from PDB-Trp cultures with water stress. This assay included 10 replicates per condition and lasted 30 days.

\subsubsection{Physiological Parameters of Plants}

Stomatal conductance (gs) data were taken on 30-day-old wheat plants (10 plants per condition). The gs was measured in the abaxial leaf using a leaf AP4 porometer (Delta-T Devices Ltd., Cambridge, UK). The total shoot of wheat plants was taken at 30 days to record fresh weight (five plants per condition) and dry weight (five plants per conditions), after maintaining plants at $65^{\circ} \mathrm{C}$ for 5 days.

\subsubsection{Biochemical Analyses of Plants}

Wheat plants of 30 days from the greenhouse assay were used to analyze several enzymatic activities. An intermediate leaf of four wheat plants was collected from each treatment and each considered condition (optimal irrigation and water stress), immediately frozen in liquid nitrogen and ground. Proteins were extracted by homogenizing $50 \mathrm{mg}$ of leaf material in $1 \mathrm{~mL}$ of $50 \mathrm{mM}$ potassium phosphate buffer $(\mathrm{pH} 7.8)$ and centrifugation at $10,000 \mathrm{rpm}$ for $20 \mathrm{~min}$ at $4{ }^{\circ} \mathrm{C}$, and later the supernatant was taken and used for the estimation of activity of superoxide dismutase (SOD), catalase (CAT) and peroxidase (POD) antioxidants enzymes. The activities of CAT and POD were determined by using a spectrophotometer as previously described [62], and one unit defined as the change of 0.01 absorbance unit per min. The activity of SOD was measured according to the previous procedure reported [62] with minor modifications. The mixture reaction contained $2 \mathrm{~mL}$ of $50 \mathrm{mM}$ potassium phosphate buffer ( $\mathrm{pH} 7.8$ ), $13 \mathrm{mM}$ methionine, $80 \mu \mathrm{M}$ nitro blue tetrazolium chloride (NBT), $15 \mu \mathrm{M}$ riboflavin, and $50 \mu \mathrm{L}$ of protein extract. One unit of SOD was considered as the amount of enzyme needed to cause $50 \%$ inhibition in the photochemical reduction of NBT. The activities of CAT, POD and SOD were expressed as 
unit per min per mg protein and data were calculated for four biological replicates per considered treatment-condition.

\subsection{3. $\mathrm{H}_{2} \mathrm{O}_{2}$ Contents in Wheat Plants}

The quantification of $\mathrm{H}_{2} \mathrm{O}_{2}$ was assayed using potassium iodide and by monitoring the absorbance at $390 \mathrm{~nm}$ as reported previously [63]. For each sample, fresh plant material was ground in liquid nitrogen and $50 \mathrm{mg}$ used for each sample. Four biological replicates per considered treatment-condition were assayed.

\subsection{Statistical Analysis}

IBM SPSS ${ }^{\circledR}$ Statistics 27 (IBM Corp.) was used for statistical analyses, through an analysis of variance (ANOVA), to test for possible interactions between the main effects (strain, culture medium, stress water) followed by a mean separation using Tukey's test $(p<0.05)$.

\section{Conclusions}

Four Trichoderma strains belonging to genotypically distant species such as T. virens T49, T. longibrachiatum T68, T. spirale T75 and T. harzianum T115 were able to produce to a greater or lesser extent not only the already known IAA and SA, but also the CK iP and $\mathrm{tZ}$. However, not all strains produced the phytohormones $\mathrm{GA}_{1}, \mathrm{GA}_{4}, \mathrm{ABA}$ and the CK DHZ. In addition, the four Trichoderma strains displayed ACCD activity. Phytohormone production depended on the strain and/or the composition of the culture medium. Trichoderma strains showed different root colonization behavior, with wheat not appearing to be a host for T68. The application of PDB cultures of Trichoderma strains can be linked to the ability of wheat plants to adapt the antioxidant machinery and to tolerate water stress. However, noninoculated PDB-Trp application made water-stressed control plants collapsed, while those treated with Trichoderma did not. In any case, the plant's ROS production and antioxidant activities of none of the treatments with addition of Trp did not seem to respond to water stress, although those corresponding to the application of Trichoderma PDB-Trp cultures showed better protection. Plants treated with T49 and T115 showed the best water stress tolerance phenotypes. Perhaps the production of $\mathrm{GA}_{4}$ by T49 and ACCD by T115 could be a cause of this good performance of the wheat plants.

Author Contributions: E.M. and R.H. conceived and designed the experiments. M.I., A.P.-M., M.P.-B. performed the experiments. All authors analyzed the data. R.H. and E.M. wrote the manuscript. All authors have read and approved the final version of the manuscript.

Funding: This research was funded by the Spanish Government, grant RTI2018-099986-B-I00, the European Regional Development Fund (FEDER) under the Regional Government of Castile and Leon support, grants SA094P20 and Escalera de Excelencia CLU-2018-04, and Provincial Council of Salamanca, Spain (Diputación projects-2018).

Institutional Review Board Statement: Not applicable.

Informed Consent Statement: Not applicable.

Data Availability Statement: Not applicable.

Acknowledgments: M.I. and M.P.-B. were granted with a predoctoral fellowship of the Regional Government of Castile and Leon, and A.P.-M. was granted with a predoctoral contract of the Regional Government of Castile and Leon (Escalera de Excelencia CLU-2018-04).

Conflicts of Interest: The authors declare no conflict of interest. 


\section{References}

1. Boivin, S.; Kazmierczak, T.; Brault, M.; Wen, J.; Gamas, P.; Mysore, K.S.; Frugier, F. Different cytokinin CHK receptors regulate nodule initiation as well as later nodule developmental stages in Medicago truncatula. Plant Cell Environ. 2016, 39, $2198-2209$. [CrossRef]

2. Egamberdieva, D.; Wirth, S.J.; Alqarawi, A.A.; Abd-Allah, E.F.; Hashem, A. Phytohormones and beneficial microbes: Essential components for plants to balance stress and fitness. Front. Microbiol. 2017, 8, 2104. [CrossRef]

3. Chanclud, E.; Morel, J.-B. Plant hormones: A fungal point of view. Mol. Plant Pathol. 2016, 17, 1289-1297. [CrossRef]

4. Khan, M.I.R.; Fatma, M.; Per, T.S.; Anjum, N.A.; Khan, N.A. Salicylic acid-induced abiotic stress tolerance and underlying mechanisms in plant. BMC Microbiol. 2012, 12, 3. [CrossRef]

5. Sanz, L.; Montero, M.; Grondona, I.; Vizcaíno, J.A.; Hermosa, R.; Llobell, A.; Monte, E. Cell wall degrading isoenzyme profiles of Trichoderma biocontrol strains have correlation with rDNA taxonomical species. Curr. Genet. 2004, 46, 277-286. [CrossRef] [PubMed]

6. Morán-Diez, E.; Hermosa, R.; Ambrosio, P.; Cardoza, R.E.; Gutiérrez, S.; Lorito, M.; Monte, E. The ThPG1 endopolygalacturonase is required for the Trichoderma harzianum-plant beneficial interaction. Mol. Plant-Microbe Interact. 2009, 22, 1021-1031. [CrossRef] [PubMed]

7. Nogueira-Lopez, G.; Greenwood, D.R.; Middleditch, M.; Winefield, C.; Eaton, C.; Steyaert, J.M.; Mendoza-Mendoza, A. The apoplastic secretome of Trichoderma virens during interaction with maize roots shows an inhibition of plant defence and scavenging oxidative stress secreted proteins. Front. Plant Sci. 2018, 59, 409. [CrossRef]

8. Carrero-Carrón, I.; Rubio, M.B.; Niño-Sánchez, J.; Navas, J.A.; Jiménez-Díaz, R.M.; Monte, E.; Hermosa, R. Interactions between Trichoderma harzianum and defoliating Verticillium dahliae in resistant and susceptible wild olive clones. Plant Pathol. 2018, 67, 1758-1767. [CrossRef]

9. Hermosa, R.; Rubio, M.B.; Cardoza, R.E.; Nicolás, C.; Monte, E.; Gutiérrez, S. The contribution of Trichoderma to balancing the costs of plant growth and defense. Int. Microbiol. 2013, 16, 69-80.

10. Mendoza-Mendoza, A.; Zaid, R.; Lawry, R.; Hermosa, R.; Monte, E.; Horwitz, B.; Mukherjee, P.K. Molecular dialogue between Trichoderma and roots. Role of the fungal secretome. Fungal Biol. Rev. 2018, 32, 62-85. [CrossRef]

11. Ramírez-Valdespino, C.A.; Casas-Flores, S.; Olmedo-Monfil, V. Trichoderma as a model to study effector-like molecules. Front. Microbiol. 2019, 10, 1030. [CrossRef]

12. Hermosa, R.; Viterbo, A.; Chet, I.; Monte, E. Plant-beneficial effects of Trichoderma and of its genes. Microbiology 2012, 158, 17-25. [CrossRef]

13. Morán-Diez, M.E.; Martínez de Alba, A.E.; Rubio, M.B.; Hermosa, R.; Monte, E. Trichoderma and the plant heritable priming responses. J. Fungi. 2021, 7, 318. [CrossRef] [PubMed]

14. Guzmán-Guzmán, P.; Porras-Troncoso, M.D.; Olmedo-Monfil, V.; Herrera-Estrella, A. Trichoderma species: Versatile plant symbionts. Phytopathology 2019, 109, 6-16. [CrossRef] [PubMed]

15. Chowdappa, P.; Kumar, S.P.M.; Lakshmi, M.J.; Upreti, K.K. Growth stimulation and induction of systemic resistance in tomato against early and late blight by Bacillus subtilis OTPB1 or Trichoderma harzianum OTPB3. Biol. Control. 2013, 65, 109-117. [CrossRef]

16. Contreras-Cornejo, H.A.; Macías-Rodríguez, L.I.; Cortés-Penagos, C.; López-Bucio, J. Trichoderma virens, a plant beneficial fungus, enhances biomass production and promotes lateral root growth through an auxin-dependent mechanism in Arabidopsis. Plant Physiol. 2009, 149, 1579-1592. [CrossRef] [PubMed]

17. Gravel, V.; Antoun, H.; Tweddell, R.J. Growth stimulation and fruit yield improvement of greenhouse tomato plants by inoculation with Pseudomonas putida or Trichoderma atroviride: Possible role of indole acetic acid (IAA). Soil Biol. Biochemist. 2007, 39, 1968-1977. [CrossRef]

18. Jaroszuk-Ściseł, J.; Tyśkiewicz, R.; Nowak, A.; Ozimek, E.; Majewska, M.; Hanaka, A.; Tyśkiewicz, K.; Pawlik, A.; Janusz, G. Phytohormones (auxin, gibberellin) and ACC deaminase in vitro synthesized by the mycoparasitic Trichoderma DEMTkZ3A0 strain and changes in the level of auxin and plant resistance markers in wheat seedlings inoculated with this strain conidia. Int. J. Mol. Sci. 2019, 20, 4923. [CrossRef]

19. Kamalov, L.S.; Turgunov, K.K.; Aripova, S.F.; Abdilalimov, O. Gibberillin A-3 from the microscopic fungus Trichoderma harzianum. Chem. Nat. Compd. 2018, 54, 421-422. [CrossRef]

20. Pérez, E.; Rubio, M.B.; Cardoza, R.E.; Gutiérrez, S.; Bettiol, W.; Monte, E.; Hermosa, R. The importance of chorismate mutase in the biocontrol potential of Trichoderma parareesei. Front. Microbiol. 2015, 6, 1181. [CrossRef]

21. Saber, W.I.A.; Ghoneem, K.M.; Rashad, Y.M.; Al-Askar, A.A. Trichoderma harzianum WKY1: An indole acetic acid producer for growth improvement and anthracnose disease control in sorghum. Biocontrol Sci. Technol. 2017, 27, 654-676. [CrossRef]

22. Zhao, L.; Zhang, Y. Effects of phosphate solubilization and phytohormone production of Trichoderma asperellum Q1 on promoting cucumber growth under salt stress. J. Integr. Agric. 2015, 14, 1588-1597. [CrossRef]

23. Rubio, M.B.; Quijada, N.M.; Pérez, E.; Domínguez, S.; Monte, E.; Hermosa, R. Identifying Trichoderma parareesei beneficial qualities for plants. Appl. Environ. Microbiol. 2014, 80, 1864-1873. [CrossRef] [PubMed]

24. Rubio, M.B.; Hermosa, R.; Vicente, R.; Gómez-Acosta, F.A.; Morcuende, R.; Monte, E.; Bettiol, W. The combination of Trichoderma harzianum and chemical fertilization leads to the deregulation of phytohormone networking, preventing the adaptative responses of tomato plants to salt stress. Front. Plant Sci. 2017, 8, 294. [CrossRef] [PubMed] 
25. Mastouri, F.; Björkman, T.; Harman, G.E. Trichoderma harzianum enhances antioxidant defense of tomato seedlings and resistance to water deficit. Mol. Plant Microbe Interact. 2012, 25, 1264-1271. [CrossRef] [PubMed]

26. Bae, H.; Sicher, R.C.; Kim, M.S.; Kim, S.H.; Strem, M.D.; Melnick, R.L.; Bailey, B.A. The beneficial endophyte Trichoderma hamatum isolate DIS 219b promotes growth and delays the onset of the drought response in Theobroma cacao. J. Exp. Bot. 2009, 60, 3279-3295. [CrossRef]

27. Guler, N.S.; Pehlivan, N.; Karaoglu, S.A.; Guzel, S.; Bozdeveci, A. Trichoderma atroviride ID20G inoculation ameliorates drought stress-induced damages by improving antioxidant defence in maize seedlings. Acta Physiol. Plant 2016, 38, 132-140. [CrossRef]

28. Pandey, V.; Ansari, M.W.; Tula, S.; Yadav, S.; Sahoo, R.K.; Shukla, N.; Bains, G.; Badal, S.; Chandra, S.; Gaur, A.K.; et al. Dosedependent response of Trichoderma harzianum in improving drought tolerance in rice genotypes. Planta 2016, 243, 1251-1264. [CrossRef]

29. Sabatini, S.; Beis, D.; Wolkenfelt, H.; Murfett, J.; Guilfoyle, T.; Malamy, J.; Benfey, P.N.; Leyser, O.; Bechtold, N.; Weisbeek, P.J.; et al. An auxin-dependent distal organizer of pattern and polarity in Arabidopsis root. Cell 1999, 99, 463-472. [CrossRef]

30. Vadassery, J.; Ritter, C.; Venus, Y.; Camehl, I.; Varma, A.; Shahollari, B.; Novák, O.; Strnad, M.; Ludwig-Müller, J.; Oelmüller, R. The role of auxins and cytokinins in the mutualistic interaction between Arabidopsis and Piriformospora indica. Mol. Plant Microbe Interact. 2008, 21, 1371-1383. [CrossRef]

31. Garnica-Vergara, A.; Barrera-Ortiz, S.; Muñoz-Parra, E.; Raya-González, J.; Méndez-Bravo, A.; Macías-Rodríguez, L.; RuizHerrera, L.J.; López-Bucio, J. The volatile 6-pentyl-2H-pyran-2-one from Trichoderma atroviride regulates Arabidopsis thaliana root morphogenesis via auxin signaling and ETHYLENE INSENSITIVE 2 functioning. New Phytol. 2016, 209, 1496-1512. [CrossRef]

32. González-Pérez, E.; Ortega-Amaro, M.A.; Salazar-Badillo, F.B.; Bautista, E.; Douterlungne, D.; Jiménez-Bremot, J.F. The ArabidopsisTrichoderma interaction reveals that the fungal growth medium is an important factor in plant growth induction. Sci. Rep. 2018, 8, 16427. [CrossRef]

33. Samolski, I.; Rincón, A.M.; Pinzón, L.M.; Viterbo, A.; Monte, E. The qid74 gene from Trichoderma harzianum has a role in root architecture and plant biofertilization. Microbiology 2012, 158, 129-138. [CrossRef] [PubMed]

34. Khan, N.A.; Khan, M.I.R.; Ferrante, A.; Poor, P. Editorial: Ethylene: A key regulatory molecule in plants. Front. Plant Sci. 2017, 8, 1782. [CrossRef] [PubMed]

35. Zhang, S.; Gan, Y.; Xu, B. Mechanisms of the IAA and ACC deaminase producing strain of Trichoderma longibrachiatum T6 in enhancing wheat seedling tolerance to $\mathrm{NaCl}$ stress. BMC Plant Biol. 2019, 19, 22. [CrossRef]

36. Viterbo, A.; Landau, U.; Kim, S.; Chernin, L.; Chet, I. Characterization of ACC deaminase from the biocontrol and plant growth-promoting agent Trichoderma asperellum T203. FEMS Microbiol. Lett. 2010, 305, 42-48. [CrossRef] [PubMed]

37. Rauf, M.; Awais, M.; Ud-Din, A.; Ali, K.; Gul, H.; Rahman, M.M.; Hamayun, M.; Arif, M. Molecular mechanisms of the 1-aminocyclopropane-1-carboxylic acid (ACC) deaminase producing Trichoderma asperellum MAP1 in enhancing wheat tolerance to waterlogging stress. Front. Plant Sci. 2021, 11, 614971. [CrossRef] [PubMed]

38. Illescas, M.; Rubio, M.B.; Hernández-Ruiz, V.; Morán-Diez, M.E.; Martínez de Alba, A.E.; Nicolás, C.; Monte, E.; Hermosa, R. Effect of inorganic $\mathrm{N}$ top dressing and Trichoderma harzianum seed-inoculation on crop yield and the shaping of root microbial communities of wheat plants cultivated under high basal $\mathrm{N}$ fertilization. Front. Plant Sci. 2020, 11, 575861. [CrossRef]

39. You, J.; Chan, Z. ROS regulation during abiotic stress responses in crop plants. Front. Plant Sci. 2015, 6, 1092. [CrossRef]

40. Rubio, M.B.; Martínez de Alba, A.E.; Nicolás, C.; Monte, E.; Hermosa, R. Early root transcriptomic changes in wheat seedlings colonized by Trichoderma harzianum under different inorganic nitrogen supplies. Front. Microbiol. 2019, 10, 2444. [CrossRef]

41. Bashyal, B.M.; Parmar, P.; Zaidi, N.W.; Aggarwal, R. Molecular programming of drought-challenged Trichoderma harzianumbioprimed rice (Oryza sativa L.). Front. Microbiol. 2021, 12, 655165. [CrossRef]

42. ICTT: International Commission on Trichoderma Taxonomy. 2021. Available online: https://trichoderma.info/ (accessed on 6 July 2021).

43. Lorito, M.; Woo, S.L.; Harman, G.E.; Monte, E. Translational research on Trichoderma: From 'omics to the field. Ann. Rev. Phytopathol. 2010, 48, 395-417. [CrossRef]

44. Harman, G.E.; Obregón, M.A.; Samuels, G.J.; Lorito, M. Changing models of biocontrol in the developing and developed world. Plant Dis. 2010, 94, 928-939. [CrossRef] [PubMed]

45. Baiyee, B.; Pornsuriya, C.; Ito, S.; Sunpapao, A. Trichoderma spirale T76-1 displays biocontrol activity against leaf spot on lettuce (Lactuca sativa L.) caused by Corynespora cassiicola or Curvularia aeria. Biol. Control. 2019, 129, 195-200. [CrossRef]

46. Zhang, S.; Xu, B.; Zhang, J.; Gean, Y. Identification of the antifungal activity of Trichoderma longibrachiatum T6 and assessment of bioactive substances in controlling phytopathogens. Pestic. Biochem. Physiol. 2018, 147, 59-66. [CrossRef] [PubMed]

47. Abbasi, N.A.; Pervaiz, T.; Hafiz, I.A.; Yaseen, M.; Hussain, A. Assessing the response of indigenous loquat cultivar Mardan to phytohormones for in vitro shoot proliferation and rooting. J. Zhejiang Univ. Sci. B 2013, 14, 774-784. [CrossRef] [PubMed]

48. Waqas, M.; Khan, A.L.; Kamran, M.; Hamayun, M.; Khang, S.-M.; Kim, Y.-H.; Lee, I.-J. Endophytic fungi produce gibberellins and indolacetic acid and promotes host-plant growth during stress. Molecules 2012, 17, 10754-10773. [CrossRef]

49. Liu, X.; Hou, X. Antagonistic regulation of ABA and GA in metabolism and signaling pathways. Front. Plant Sci. 2018, 9, 251. [CrossRef] [PubMed]

50. Cai, F.; Druzhinina, I.S. In honor of John Bissett: Authoritative guidelines on molecular identification of Trichoderma. Fungal Divers. 2021, 107, 1-69. [CrossRef] 
51. Rubio, M.B.; Domínguez, S.; Monte, E.; Hermosa, R. Comparative study of Trichoderma gene expression in interactions with tomato plants using high-density oligonucleotide microarrays. Microbiology 2012, 158, 119-128. [CrossRef]

52. Schweiger, R.; Padilla-Arizmendi, F.; Nogueira-López, G.; Rostás, M.; Lawry, R.; Brown, C.; Hampton, J.; Steyaert, J.M.; Müller, C.; Mendoza-Mendoza, A. Insights into metabolic changes caused by the Trichoderma virens-maize root interaction. Mol. Plant Microbe Interact. 2021, 34, 524-537. [CrossRef] [PubMed]

53. Scudeletti, D.; Crusciol, C.A.C.; Bossolani, J.W.; Moretti, L.G.; Momesso, L.; Servaz-Tubaña, B.; de Castro, S.G.Q.; De Oliveira, E.F.; Hungria, M. Trichoderma asperellum inoculation as a tool for attenuating drought stress in sugarcane. Front. Plant Sci. 2021, 12, 645542. [CrossRef] [PubMed]

54. Aamir, M.; Kashyap, S.P.; Zehra, A.; Dubey, M.K.; Singh, V.K.; Ansarii, W.A.; Upadhyay, R.S.; Singh, S. Trichoderma erinaceum bio-priming modulates the WRKYs defense programming in tomato against the Fusarium oxysporum $\mathrm{f}$. sp. lycopersici (Fol) challenged condition. Front. Plant Sci. 2019, 10, 911. [CrossRef] [PubMed]

55. Pehlivan, N.; Yesilyurt, A.M.; Durmus, N.; Karaoglu, S.A. Trichoderma lixii ID11D seed biopriming mitigates dose dependent salt toxicity in maize. Acta Physiol. Plant. 2017, 39, 79. [CrossRef]

56. Hermosa, M.R.; Keck, E.J.; Chamorro, I.; Rubio, M.B.; Sanz, L.; Vizcaíno, J.A.; Grondona, I.; Monte, E. Genetic variability shown by a collection of biocontrol isolates of Trichoderma. Mycol. Res. 2004, 108, 897-906. [CrossRef]

57. Raeder, U.; Broda, P. Rapid preparation of DNA from filamentous fungi. Lett. Appl. Microbiol. 1985, 1, 17-20. [CrossRef]

58. Sadfi-Zouaoui, N.; Hannachi, I.; Rouaissi, M.; Hajlaoui, M.R.; Rubio, M.B.; Monte, E.; Boudabous, A.; Hermosa, R. Biodiversity of Trichoderma isolates in Tunisia. Can. J. Microbiol. 2009, 55, 154-162. [CrossRef]

59. Yedidia, I.; Benhamou, N.; Chet, I. Induction of defense responses in cucumber plants (Cucumis sativus L.) by the biocontrol agent Trichoderma harzianum. Appl. Environ. Microbiol. 1999, 65, 1061-1070.

60. Bradford, M.M. A rapid and sensitive method for the quantitation of microgram quantities of protein utilizing the principle of protein-dye binding. Anal. Biochem. 1976, 72, 248-254. [CrossRef]

61. Seo, M.; Jikumaru, Y.; Kamiya, Y. Profiling of hormones and related metabolites in seed dormancy and germination studies. Methods Mol. Biol. 2011, 773, 99-111.

62. Nawaz, A.; Shahbaz, M.; Asadullah; Imran, A.; Marghoob, M.U.; Imtiaz, M.; Mubeen, F. Potential of salt tolerant PGPR in growth and yield augmentation of wheat (Triticum aestivum L.) under saline conditions. Front. Microbiol. 2020, 11, 2019. [CrossRef] [PubMed]

63. Velikova, V.; Yordanov, I.; Edreva, A. Oxidative stress and some antioxidants systems in acid rain-treated bean plants. Plant Sci. 2000, 151, 59-66. [CrossRef] 